\title{
Peculiar evolution of streptococcal skin infections
}

\author{
Sonia Drăghici*, Andrei Csep \\ From The 9th Edition of the Scientific Days of the National Institute for Infectious Diseases Prof Dr Matei Bals \\ Bucharest, Romania. 23-25 October 2013
}

\section{Background}

Acute Streptococcus pyogenes infections may present under various forms, such as pharyngitis, scarlet fever, pneumonia, meningitis, cellulitis or impetigo. Toxigenic infections can result in necrotizing fasciitis, myositis and streptococcal toxic shock syndrome. Following acute infections caused by $S$ pyogenes, patients are also at risk for developing immune-mediated post-streptococcal sequelae, as is the case with acute rheumatic fever and acute glomerulonephritis.

\section{Methods}

We performed a hospital based study from January 2012 to December 2012 in the Clinic of Infectious Diseases Oradea.

\section{Results}

A total number of 192 patients were studied during a one-year period: 25 cases of impetigo and erysipelas, in parallel with 84 cases of tonsillitis, 36 cases of scarlet fever, 10 cases of acute rheumatic fever, 8 cases of chronic rheumatic heart disease, 6 cases of acute post streptococcal glomerulonephritis, 2 cases of streptococcal meningitis, and 31 cases of healthy carriers of $S$ pyogenes.

Impetigo dominated in children (7 cases $-70 \%)$ vs. adults (3 cases $-30 \%$ ); erysipelas dominated in adults, especially over 40 years (13 cases $-86 \%)$ vs. children ( 2 cases $-14 \%)$. From the 25 patients admitted in the hospital with the diagnosis of erysipelas, 11 patients $(60 \%)$ declared one or more (5) recurrences in the same part of the body. In rheumatic fever, approximately $80 \%$ of the patients will have an elevated ASO titer $(>200$ Todd units) at 2 months after onset.

\section{Conclusion}

The type and severity of streptococcal infections depends on the strain of $S$ pyogenes and on the

* Correspondence: sonia_draghici@yahoo.com

Faculty of Medicine and Pharmacy, University of Oradea, Romania comorbid conditions or diseases, like heart, pulmonary, renal, metabolic chronic diseases, obesity or lymphatic stasis.

The septic, toxic and the immune complications of streptococcal infections pose important problems for the public health services.

Published: 16 December 2013

doi:10.1186/1471-2334-13-S1-P66

Cite this article as: Drăghici and Csep: Peculiar evolution of streptococcal

skin infections. BMC Infectious Diseases 2013 13(Suppl 1):P66.
Submit your next manuscript to BioMed Central and take full advantage of:

- Convenient online submission

- Thorough peer review

- No space constraints or color figure charges

- Immediate publication on acceptance

- Inclusion in PubMed, CAS, Scopus and Google Scholar

- Research which is freely available for redistribution
() Biomed Central

\section{Ciomed Central}

